\title{
В ЦЕНТРЕ ВНИМАНИЯ интеллектуалыные транспортные системы
}

Транспорт - одна из тех отраслей, где за цифровизацию уже взялись всерьез как в центре, так и в регионах. В этом можно было убедиться на в пятый раз организованном Ассоциацией "Цифровая Эра Транспорта" форуме "Интеллектуальные транспортные системы России: цифровая эра транспорта", который прошел в столице 7-8 октября. Оператором мероприятия традиционно выступило коммуникационное агентство "J Comm события и технологии". Форум стал главной площадкой в стране, которая собирает заказчиков и поставщиков решений на стыке транспорта, телекоммуникаций и ИТ. Ключевой темой юбилейного события организаторами была объявлена: "Что? Где? Когда?" в цифровой трансформации транспортного комплекса".

Ведущая в стране площадка по обсуждению цифровой трансформации транспортного комплекса, и в первую очередь интеллектуальных транспортных систем (ИТС), собрала в этот раз более 150 участников. В отличие от прошлых лет, их встречали не только стенды с новейшими разработками в области цифровых технологий для транспорта, но и уже привычные сотрудники с электронными термометрами, а вместе с бейджами выдавались маски. Реалии "коронавирусного" мира вносят корректировки во все сферы жизни, включая развитие и внедрение ИТС. Хочется надеяться, что эти системы оптимально обеспечат, в частности, минимизацию скоплений людей на всех видах транспорта.

На форуме представители Министерства транспорта Российской Федерации, Федерального дорожного агентства (Росавтодор), ФАУ "РОСДОРНИИ", Ассоциации "Цифровая Эра Транспорта", Ассоциации производителей и операторов систем распознавания и фотовидеофиксации "ОКО", холдинга "Швабе", оператора связи "ВымпелКом", а также представители более 20 региональных министерств и ведомств, эксперты, руководители ведущих компаний отрасли обсудили вопросы цифровой трансформации транспортного комплекса страны, развитие сети общественного транспорта, внедрение беспилотных технологий, вопросы транспортного планирования и моделирования городских агломераций и др. Одним из ключевых направлений форума стала тема реализации программы внедрения ИТС в регионах в рамках нацпроекта "Безопасные и качественные автомобильные дороги".

Форум открылся пленарной дискуссией "Цифровая трансформация транспортного комплекса". Как ИТС Москвы помогла справиться с распространением COVID-19, какова должна быть цифровая инфраструктура автомобильной дороги, как добиться интеграции региональных и федеральных ИТС, как спад экономики отразился на планах по цифровизации транспортной отрасли и какие инструменты поддержки со стороны государства могли бы стимулировать ее развитие - часть тем, которые обсудили участники сессии.

По словам Павла Ручьева, начальника управления регионального развития и реализации национального проекта Федерального 


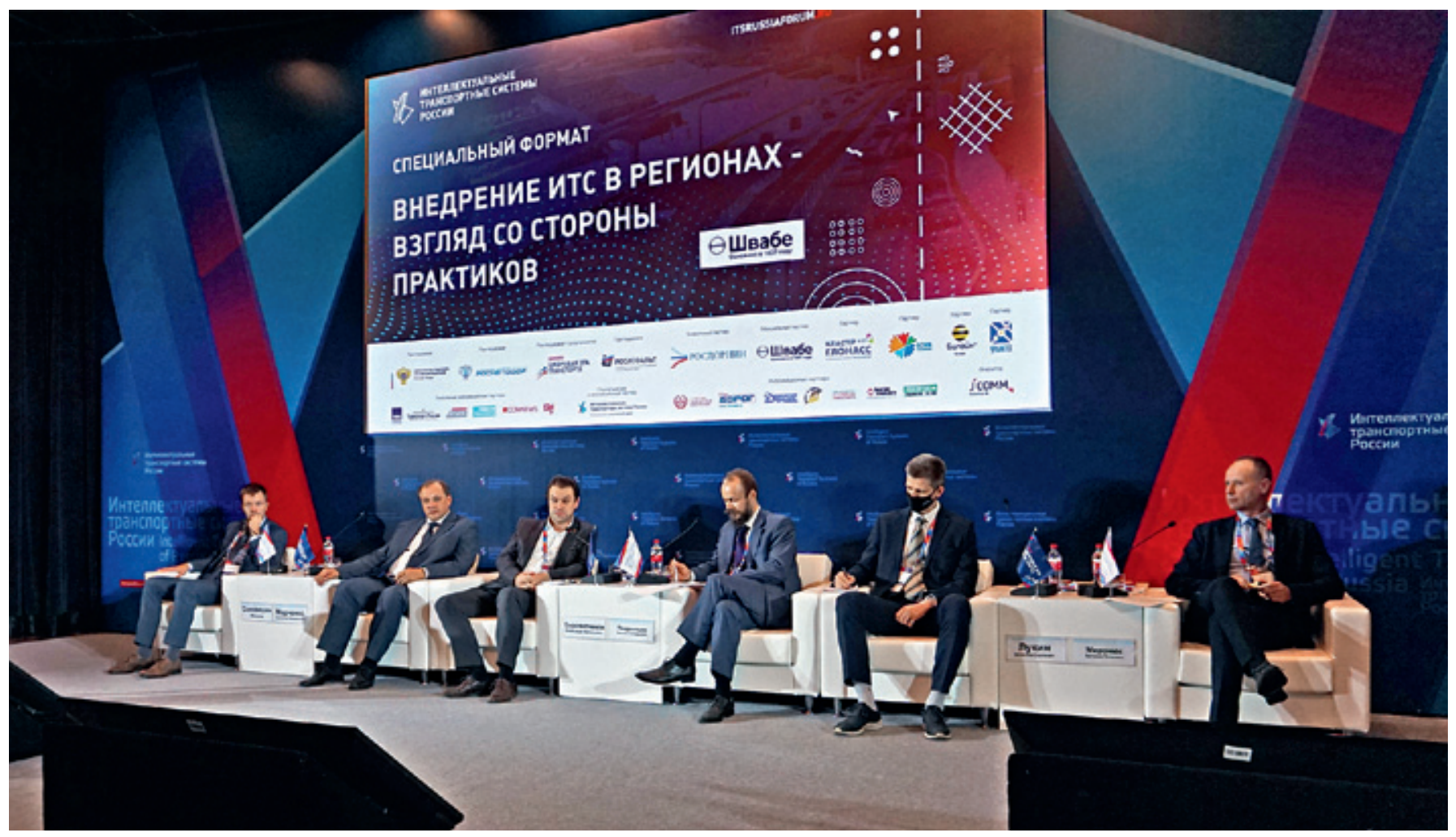

дорожного агентства, эффект от применения интеллектуальных транспортных систем огромный. При этом вопросов очень много.

"Мы наблюдаем несбалансированность между потребностями транспортных услуг и реальной пропускной способностью. На сегодняшний день происходит значительный рост использования личного и общественного транспорта. Действующая инфраструктура, которая должна обеспечить пропускную способность, не справляется. И мы сталкиваемся с проблемами безопасности, с проблемами обеспечения грузоперевозок, качества предоставляемых услуг. Поэтому важная задача, которую мы ставим перед собой - это развитие ИТС, способных помочь нам в преодолении и решении проблем пропускной способности, проблем безопасности дорожного движения, повышения эффективности логистических процессов при грузоперевозках", - отметил представитель Росавтодора.

Екатерина Брязгина, директор по развитию ФАУ "РОСДОРНИИ", отметила, что цифровая трансформация - это новые возможности, процессы и сервисы. Это новое, необходимое и, самое главное, очень эффективное.

"Для ФАУ "РОСДОРНИИ" и для всей отрасли это синергия транспортного моделирования, ИТС, систем фотовидеофиксации ПдД, систем весогабаритного контроля, всего массива информации и других систем для повышения качества, безопасности и внедрения новейших технологий и грандиозных масштабных задач, таких как введение на дороги общего пользования беспилотного транспорта", - подчеркнула докладчица .

Один из ключевых вопросов, который затронула директор по развитию ФАУ "РОСДОРНИИ", - экономический кризис: "Спад экономики повлияет на цифровую трансформацию транспортного комплекса. Но плохо ли это? С одной стороны, да - будет меньше технологических возможностей и возможностей взаимодействия с коллегами в регионах, других странах. Но, с другой стороны, для нас всех - это хорошая возможность в спокойном режиме доработки документов, методических рекомендаций по разработке документов транспортного планирования субъектов Российской Федерации, а также правовых актов и нормативно-технических документов", - уточнила Е.Брязгина.

Генеральный директор АНО "Дирекция Московского транспортного узла" Алексей Петров и заместитель директора ООО "ШвабеМосква" Иван Морданов поделились опытом внедрения ИТС в столице и рассказали о перспективах развития ИТС в регионах. 


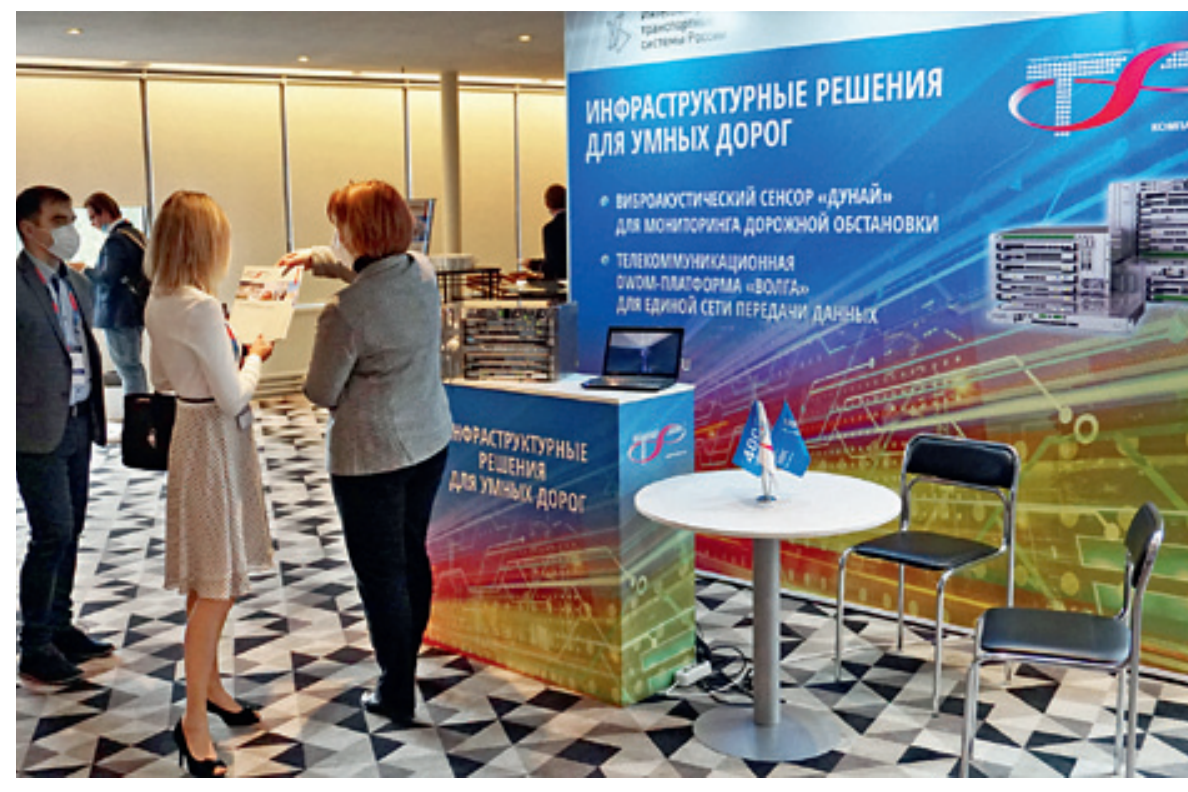

Стенд компании "Т8"

регионов - это большая проблема. Ведь одно дело установить, а другое дело - эксплуатировать. И проблемы при эксплуатации интеллектуальных транспортных систем в регионах колоссальные", - подчер кнул И.Морданов.

Во второй день в рамках форума при участии Федерального дорожного агент ства прошло совещание по реализации программы внедрения ИТС в регионах в рамках нацпроекта "Безопасные и качественные автомобильные дороги". На совещании присут ствовало более 100 представителей из 35 субъектов Федерации.

Еще весной текущего года Росавтодор рассмотрел заявки

"В рамках разрабатываемой под руководством AHO "ДМту" Стратегии развития транспортной системы г. Москвы и Московской области на период до 2035 года подготовлен технологический прогноз внедрения цифровых и инновационных технологий в транспортный комплекс Москвы и Московской области", - рассказал Алексей Петров. Как отметил руководитель АНО "ДМту", транспортная система Москвы считается одной из самых передовых в области цифровизации. Однако это не значит, что мы должны останавливаться на достигнутом.

"Нам нужно двигаться дальше по пути цифровой трансформации, следуя за развитием инновационных технологий и трендов в области цифровизации. Очень многое, что касательно регионов, зависит от бюджетных средств, выделяемых в субъект на тот или иной проект. Очень важно помогать регионам, внедрять ИТС на дальних межрегиональных магистралях, двигаясь по пути расширения внедрения цифровых систем на ключевые связующие коридоры", - рассказал А.Петров.

В продолжении темы Иван Морданов рассказал, что на опыте концерна и опыте обслуживания ИТС Москвы вскрывается проблема дальнейшего обслуживания и эксплуатации систем интеллектуальных транспортных систем в регионах. "Мы, как практики, не понимаем, почему про ИТС все мы говорим исключительно на теоретическом уровне. ИТС - это огромные расходы, колоссаль ные средства для обслуживания систем. И для от регионов на выделение в рамках национального проекта средств для внедрения интеллектуаль ных транспортных систем, предусматривающих автоматизацию процессов управления дорожным движением и включающих города с населением свыше 300 тыс. человек. Всего в агентство поступило 56 заявок от 50 субъектов РФ, из которых было отобрано 22 региональных проекта. Объем финан сирования в 2020 году - более 3,3 млрд руб.

По словам Екатерины Брязгиной (ФАУ "РОсдОРНИИ"), регионы уже провели кон курсные процедуры и заключили контракты на сумму более 500 млн руб., при этом экономия бюджетных средств составила более 65,3 млн. На 51\% оставшихся средств торги объявлены, еще на 31\% идет подготовка документации. Этот вопрос находится на жестком контроле федерального центра.

"Крайне важно понимать, что регионы реализуют мероприятия в соответствии с поданными заявками, а денежные средства осваиваются целевым образом", - подчеркнула Е.Брязгина.

Представителями региональных проектных офисов были подняты проблемные вопросы, возникшие в ходе реализации программы внедрения ИТС в городских агломерациях, касающихся разработки проектной документации, проведения конкурсных процедур и качества технических заданий. Нехватка кадров, необходимость формирования компетенций на должном уровне в регионах - неполный перечень тем, поднятых на мероприятии. 
В некоторых субъектах РФ интеллектуальные транспортные системы в том или ином виде существуют уже давно - это комплексы фотовидеофиксации нарушений правил дорожного движения, автоматические пункты весогабаритного контроля, системы мониторинга параметров транспортного потока, метеомониторинга. Одной из важнейших задач, стоящих перед субъектами, является обеспечение интеграции и взаимоувязки уже существующих подсистем и создание условий для их оптимизации в будущем. Причем, по словам заместителя руководителя Федерального дорожного агентства Игоря Костюченко, речь идет как о межведомственной, так и о межсубъектной интеграции.

"ИТС - это не локальная задача какой-то одной агломерации, это задача для Российской Федерации в целом. Важно, как предложение одного субъекта ляжет в концепт в масштабах всей страны. Поэтому при подготовке таких предложений всегда необходимо думать над приоритетами, думать на перспективу", - подчеркнул заместитель руководителя Росавтодора.

Он также отметил: "Важность и значимость реализации проектов в области внедрения интеллектуальных транспортных систем в регионах мы все прекрасно понимаем. Действительно, управление процессом должно быть на уровне субъекта, и развитие ИТС должно строиться по модульному принципу, исходя из периферийного оборудования. Но, тем не менее, концепт должен быть заложен на этапе проектной разработки".

Программа форума включала также сессии "Подключенный и высокоавтоматизированный транспорт: ожидания и реальность"; "Комфортная городская среда: инфраструктура, мобильность, общественный транспорт"; "Внедрение ИТС в регионах - взгляд со стороны практиков".

Отметим, что в сессии "Цифровая инфраструктура автомобильных дорог" уже традиционно участвовала компания "Т8", известная многим связистам страны своим передовым высокоскоростным оборудованием систем передачи. На данном форуме ею были представлены последние достижения, в частности, в совершенствовании виброакустического сенсора "Дунай". Данное инновационное решение, основанное на использовании свойств волокон в обычном оптическом кабеле, обеспечивает интеллектуальный мониторинг в том числе дорожной обстановки.

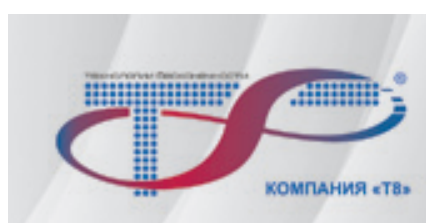

OБОРУАОВАНИЕ POССИЙСКОГО ПРОИСХОЖАЕНИЯ ОФИЧИАМЬНЫЙ СТАТУС
МИНПТОМТОРТА РОССИИ

-Т8. - веАущий разработчик и производитель телекоммуникационного оборудования спектрального упмотнения (DWDM) Аля оптических сетей связи в России и странах СНГ. Мы премлагаем компмексные решения по построению DWDM-сетей поА киюч.

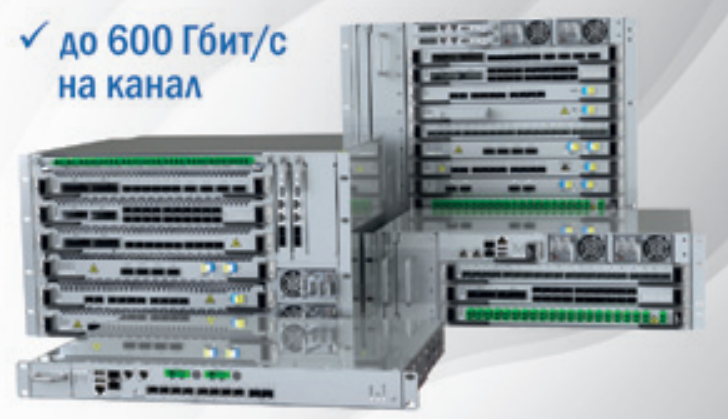

ПЛАТФОРМА "ВОЛГА"

\section{РЕШЕНИЯ АЯ ОПТИЧЕСКИХ СЕТЕЙ:}

- MAГИСТPAAЬHЫE DWDM-CETИ

- РЕГИОНАЛЬНЫЕ И ГОРОАСКИЕ ВОЛС

- AАТА-ЦЕНТРЫ

- TPAнСПОРТНЫЕ CETИ 5G

- ТЕХНОЛОГИЯ «ЧУЖОЙ АЛИНЫ ВОАНЫ»

$$
\text { WWW.T8.RU }
$$

\section{Российское оборудование мирового класса!}

ЧЕМПИОНЫ 